Article

\title{
New 19-Residue Peptaibols from Trichoderma Clade Viride
}

\author{
Tamás Marik ${ }^{1}$, Chetna Tyagi ${ }^{1,2}$ (D) , Gordana Racić ${ }^{3}$, Dávid Rakk ${ }^{1,2}$, András Szekeres ${ }^{1}$, \\ Csaba Vágvölgyi ${ }^{1}$ (iD and László Kredics ${ }^{1, * \text { (D) }}$ \\ 1 Department of Microbiology, Faculty of Science and Informatics, University of Szeged, Közép fasor 52, \\ H-6726 Szeged, Hungary; mariktamas88@gmail.com (T.M.); cheta231@gmail.com (C.T.); \\ rakkdavid@gmail.com (D.R.); andras.j.szekeres@gmail.com (A.S.); csaba@bio.u-szeged.hu (C.V.) \\ 2 Doctoral School in Biology, Faculty of Science and Informatics, University of Szeged, \\ H-6726 Szeged, Hungary \\ 3 Faculty of Environmental Protection, Educons University, Vojvode Putnika 87, 21208 Sremska Kamenica, \\ Serbia; gordana.racic84@gmail.com \\ * Correspondence: kredics@bio.u-szeged.hu; Tel.: +36-62-544-516
}

Received: 2 July 2018; Accepted: 10 August 2018; Published: 12 August 2018

\begin{abstract}
Trichoderma koningiopsis and T. gamsii belong to clade Viride of Trichoderma, the largest and most diverse group of this genus. They produce a wide range of bioactive secondary metabolites, including peptaibols with antibacterial, antifungal, and antiviral properties. The unusual amino acid residues of peptaibols, i.e., $\alpha$-aminoisobutyric acid (Aib), isovaline (Iva), and the C-terminal 1,2-amino alcohol make them unique among peptides. In this study, the peptaibiomes of $T$. koningiopsis and T. gamsii were investigated by HPLC-ESI-MS. The examined strains appeared to produce 19-residue peptaibols, most of which are unknown from literature, but their amino acid sequences are similar to those of trikoningins, tricholongins, trichostrigocins, trichorzianins, and trichorzins. A new group of peptaibols detected in T. koningiopsis are described here under the name "Koningiopsin". Trikoningin KA V, the closest peptaibol compound to the peptaibols produced by these two strains, was selected for structural investigation by short MD simulation, which revealed that many residues show high preference for left handed helix formation. The bioactivity of the peptaibol mixtures produced by T. koningiopsis and T. gamsii was tested on agar plates against bacteria, yeasts, and filamentous fungi. The results revealed characteristic differences in bioactivities towards the different groups of target microorganisms, which can be explained with the differences in their cell wall structures.
\end{abstract}

Keywords: Trichoderma; Viride clade; peptaibol; liquid chromatography; mass spectrometry; bioactivity

\section{Introduction}

Within the filamentous fungal genus Trichoderma (Ascomycota, Hypocreales, Hypocreaceae) comprising more than 250 species [1], clade Viride forms one of the largest and most diverse groups. The majority of Trichoderma species were described after the year 2000, only a few species were initially included in the genus [2,3]. Bissett [4] proposed to include H. rufa/T. viride and its relatives in Trichoderma section Trichoderma along with T. koningii Oudem. and T. atroviride P. Karst. The monophyly of this group, earlier referred to as Trichoderma section Trichoderma [5] and recently as clade Viride, was confirmed after DNA sequence analysis of the internal transcribed spacers 1 and 2 (ITS 1 and 2), as well as fragments of the actin (act), calmodulin (cal) and translation elongation factor $1 \alpha(t e f 1)$ genes [6]. Since the work of Lieckfeldt et al. [7], many additional species and cultures referable to clade Viride were obtained and the taxonomy of this clade has also been revised [8]. Species in this clade can be isolated from very diverse sources with a wide geographic distribution [9] and they were also reported as beneficial organisms of industrial, agricultural, and medicinal fields [10,11]. 
Trichoderma species are known to produce a broad range of bioactive secondary metabolites with antibacterial, antifungal, and antiviral properties [12]. Among them, peptaibols are non-ribosomal peptides containing unusual amino acid residues like $\alpha$-aminoisobutyric acid (Aib), as well as isovaline (Iva), and a C-terminal 1,2-amino alcohol (e.g., Leuol, Valol, Pheol, Tyrol, Ileol, Alaol, or Prool) [13,14]. The biosynthesis of these peptides significantly differs from the ribosomal pathway: they are assembled by large, modular enzymes known as non-ribosomal peptide synthetases (NRPS) $[15,16]$. The amino acid sequence of peptaibols usually appears as a short linear helical structure, therefore several molecules need to aggregate for the formation of ion channels, which are able to cause membrane damage in lipid bilayers [17].

The information available in the literature about the peptaibol profiles of T. koningiopsis and T. gamsii is limited. Peptaibols produced by T. koningiopsis were previously identified as trikoningin KA V, together with other 11-residue compounds, trikoningin KB I and KB II [18]. To the best of our knowledge, other peptaibol compounds produced by T. koningiopsis were not previously reported in the literature. Trichoderma gamsii is a widespread species of the genus, also known as an endophyte of the traditional Chinese medicinal plant Panax notoginseng. Although the investigation of peptaibol production was not yet carried out for this species, T. gamsii was shown to produce numerous secondary metabolites including cytochalasans [19-22], the spiro-cytochalasan trichodermone [21], trichoderamides $\mathrm{A}$ and $\mathrm{B}$ originating from the PKS-NRPS hybrid pathway [23], trichodenols A and B [23], trichoderpyrone [24], as well as volatile organic compounds like dimethyl disulfide, dibenzofuran, methanethiol, and ketones [25]. Among the detected cytochalasans (trichalasins A, B, C, D, E, F, G, H, aspochalasins D, I, J, K, M, P, and aspergillin PZ), aspochalasins D and I displayed weak inhibitory activity against the HeLa cancer cell line $[19,20]$, trichalasin G proved to be modestly inhibitory to the human cancer cell line MDA-MB-231 [22], while trichoderpyrone displayed weak cytotoxic activities against A549, HepG2, and HeLa cancer cell lines [24].

The aim of the present study was to investigate the peptaibiomes of these two species and to characterise their antibiotic activity against a broad spectrum of microorganisms.

\section{Materials and Methods}

\subsection{Strains and Culture Conditions}

All strains used in this study are deposited in the Szeged Microbiology Collection (SZMC; www.szmc.hu). The Trichoderma strains selected for the investigation of their peptaibol production, T. gamsii SZMC 1656 and T. koningiopsis SZMC 12500, were identified by Nucleotide BLAST analysis (https://blast.ncbi.nlm.nih.gov/Blast.cgi) of a part of the tef 1 gene amplified according to Castagnoli et al. [26], and proved to be very closely related to T. gamsii S582 (GenBank: KJ665495) and T. koningiopsis UNISS 17b-36a (GenBank: EF488124), respectively. Both Trichoderma strains were maintained on malt extract agar (MEA) supplemented with yeast extract $\left(0.25 \mathrm{~g} \mathrm{~L}^{-1}\right.$ yeast extract, $0.5 \mathrm{~g} \mathrm{~L}^{-1}$ malt extract, $1 \mathrm{~g} \mathrm{~L}^{-1}$ glucose, $2 \mathrm{~g} \mathrm{~L}^{-1}$ agar in distilled water; $\mathrm{pH}$ 6.5). To increase peptaibol production, strains were inoculated to large $(40 \times 40 \mathrm{~cm})$ plates containing malt extract agar (MEA) medium (30 $\mathrm{g} \mathrm{L}^{-1}$ malt extract, $3 \mathrm{~g} \mathrm{~L}^{-1}$ soy peptone, $15 \mathrm{~g} \mathrm{~L}^{-1}$ agar in distilled water; $\mathrm{pH} 5.5$ ) and incubated for 7 days at $25^{\circ} \mathrm{C}$. Bacteria (Escherichia coli SZMC 0582, Micrococcus luteus SZMC 0264 Pseudomonas aeruginosa SZMC 0568, Staphylococcus aureus SZMC 0579) and fungi (Candida boidinii SZMC 0673, Kluyveromyces lactis SZMC 0683, Saccharomyces cerevisiae SZMC 0425, Schizosaccharomyces pombe SZMC 0142, Alternaria alternata SZMC 16085, Fusarium solani species complex SZMC 11467, Rhizoctonia solani SZMC 6252J, Phoma cucurbitacearum SZMC 16088, T. aggressivum f. europaeum SZMC 1811, T. pleuroti SZMC 12454, T. koningiopsis SZMC 12500, T. gamsii SZMC 1656) involved in the bioactivity tests were maintained on LB (Luria-Bertani) agar medium $\left(10 \mathrm{~g} \mathrm{~L}^{-1}\right.$ tryptone, $5 \mathrm{~g} \mathrm{~L}^{-1}$ yeast extract, $10 \mathrm{~g} \mathrm{~L}^{-1} \mathrm{NaCl}$ and $20 \mathrm{~g} \mathrm{~L}^{-1}$ agar-agar in distilled water; $\mathrm{pH}$ 7) and MEA completed with yeast extract (see above), respectively. 


\subsection{Peptaibol Extraction}

After 7 days of incubation on MEA medium, mycelium of the cultures was harvested from the plates and collected. Then, $300 \mathrm{~mL}$ chloroform/methanol 2/1 $(v / v)$ solution was added and the mixture was shaken for $2 \mathrm{~h}$. The lower phase was collected and evaporated to dryness (IKA RV 10; IKA Works, Wilmington, NC, USA), The extraction steps were repeated three times in total. After the extraction, the dry residue was dissolved in $\mathrm{MeOH}$, centrifuged in a Biofuge Primo centrifuge (Heraeus, Hanau, Germany) and stored at $-20^{\circ} \mathrm{C}$. The samples were diluted $100 \times$ for HPLC-MS analysis and set to $100 \mu \mathrm{g} \mathrm{mL}{ }^{-1}$ for inhibition tests.

\subsection{Analytical Procedures}

The crude peptaibol extracts were measured by using an HPLC-ESI-MS instrument with an Agilent 1100 system (Agilent Technologies, Palo Alto, CA, USA) controlled by a ChemStation software (A09.03; Agilent Technologies, Palo Alto, CA, USA). The system was equipped with a binary pump, a vacuum degasser, a $\mu$ Well-plate autosampler, as well as a Jones Model 7990 Space column heater (Jones Chromatography Ltd., Lakewood, CO, USA). Peptaibol separation was carried out on Gemini NX-C18 HPLC column (150 mm × $2.0 \mathrm{~mm}, 3 \mu \mathrm{m}$; Phenomenex Inc., Torrance, CA, USA). Solvent A was $\mathrm{H}_{2} \mathrm{O}$ with $0.05 \%(v / v)$ trifluoroacetic acid (TFA), while Solvent B was acetonitrile/methanol $1 / 1(v / v)$ with $0.05 \%(v / v)$ TFA. The flow rate was set to $0.2 \mathrm{~mL} \mathrm{~min}^{-1}$, the gradient program for Solvent B to $65 \%-0 \mathrm{~min}, 65 \%-5 \mathrm{~min}, 80 \%-45 \mathrm{~min}, 100 \%-70 \mathrm{~min}, 100 \%-75 \mathrm{~min}, 65 \%-76 \mathrm{~min}$, $65 \%-81 \mathrm{~min}$, the column temperature to $40{ }^{\circ} \mathrm{C}$, and the injection volume to $5 \mu \mathrm{L}$. The ESI-IT-MS instrument was Varian 500 MS (Agilent Technologies, Palo Alto, CA, USA) with ESI source in positive mode at normal scan speed and controlled by the 500-MS Mass Spec module driver of the Varian Workstation software (6.6/SP1; Varian Inc., Palo Alto, CA, USA). ESI parameters were set to the following values: spray chamber temperature: $50{ }^{\circ} \mathrm{C}$, drying gas $\left(\mathrm{N}_{2}\right)$ pressure: 30 psi, drying gas temperature: $350{ }^{\circ} \mathrm{C}$, nebuliser gas $\left(\mathrm{N}_{2}\right)$ pressure: 50 psi, needle voltage: $5704 \mathrm{~V}$, spray shield voltage: $600 \mathrm{~V}$. The general parameters were set as the maximum scan times at 2.78, $2 \mu$ Scans averaged, data rate at $0.36 \mathrm{~Hz}$ and multiplier offset at 0 . The ionization control parameters were set as target TIC wet at $100 \%$ and max ion time at $250,000 \mu \mathrm{sec}$, scan parameters as capillary voltage was set at $66 \mathrm{~V}, \mathrm{RF}$ loading at $147 \%$, while the MS scan parameters were set as low mass $m / z$ at 100 , high mass $m / z$ at 2000. The $\mathrm{MS}^{2}$ measurements of selected $\mathrm{y}_{7}$ fragments were carried out with the following excitation storage level $(\mathrm{m} / \mathrm{z})$ /excitation amplitude (V) conditions: $\mathrm{m} / \mathrm{z} 754.5(204.5 / 2.95), \mathrm{m} / \mathrm{z} 755.5(204.8 / 2.96) \mathrm{m} / \mathrm{z} 768.5$ (208.0/3.00), and $m / z 769.5$ (208.3/3.00).

Based on a calibration with alamethicin standard (Sigma-Aldrich Ltd., Budapest, Hungary), the peptaibol contents of the crude extracts were also calculated.

\subsection{Nomenclature of the Identified Peptaibols}

The newly identified peptaibol compounds obtained from T. gamsii SZMC 1656 were named according to their elution order (I, II, .. n), attached to the prefix 'Pept'. In the case of compounds eluting close to each other and differing in their characteristic ion fragments $\left(b_{12}\right.$ and $\left.y_{7}\right)$, Latin letters ( $a$ and $b$ ) are following the Roman numerals. The sequences obtained from T. koningiopsis SZMC 12500 were named Koningiopsins and numbered with Roman numerals (I, II, . . n) based on the elution order, and the different variants are distinguished by Latin letters ( $a$ and $b$ ) as mentioned before.

\subsection{Sequence Selection and Force Field Library Generation for Non-Standard Residues}

Trikoningin KA V (TKV) with the primary structure of AcAib ${ }^{1}-G_{1 y}^{2}-A_{1 a}^{3}-A_{i b}^{4}-I l e^{5}-G_{1}{ }^{6}-A_{i b}{ }^{7}$ $\mathrm{Aib}^{8}-\mathrm{Aib}^{9}-$ Ser $^{10}$-Leu ${ }^{11}-\mathrm{Aib}^{12}-$ Pro $^{13}-\mathrm{Val}^{14}-\mathrm{Aib}^{15}-\mathrm{Ile}^{16}-\mathrm{Gln}^{17}-\mathrm{Gln}^{18}$-Leuol ${ }^{19}$ was selected for molecular dynamics studies. Aib and Leuol are non-standard (non-proteinogenic) amino acid residues in the selected sequence. The R.E.D server [27] was used for calculation of their partial charges and creating force field libraries. R.E.D stands for RESP ESP charge derive [28]. RESP (restrained electrostatic 
potential) was used to calculate the charges with a HF/6-311G(d) basis set and Gaussian09 as quantum mechanical program interface. For the Aib residue, two conformations, i.e., $\alpha$-helix $(\Phi=-63.8$, $\Psi=-38.3)$ and $\beta$-sheet or $C_{5}(\Phi=-157.2, \Psi=161.9)$ were used. These were modified based on the strategy described by Cieplak et al. [29]. A slightly different strategy was used to calculate the charges for Leuol where two molecules, ethanol and Leu, were used to form the Leuol unit. The results include the charges calculated in the molecule files and a script to make force field libraries for these forces (Supplementary Data 1). The sequence was built by supplying residue units from the scratch using "tleap" after sourcing the library files of non-standard amino acids.

\subsection{Molecular Dynamics Simulations of Trikoningin KA V}

The MD calculation was carried out with Amber14 [30] using ff14SB force field available on the NIIF server via University of Szeged. The first step was "energy minimization" to stabilize the system. The maximum number of cycles was set at 10,000 (maxcyc) with convergence criteria of 0.01. The Steepest descent algorithm was used for the first 100 cycles (ncyc) and then switched to conjugate-gradient algorithm. The energy minimization outputs were used for setting up the production run with 50,000,000 steps which correspond to 10,000 ps (frames) and therefore, $100 \mathrm{~ns}$ of total simulation time. The generalized born implicit solvent method was used to study this system. The whole system was maintained at $300 \mathrm{~K}$ using Langevin thermostat $(\mathrm{ntt}=3$, gamma $\ln =1.0$ ). The time step was set to $2 \mathrm{fs}$ and no cutoff was applied for non-bonding interactions. The resultant trajectories were visualized in VMD (Visual Molecular Dynamics) [31]. Further secondary structure analysis was done by cpptraj [32] module of AmberTools18.

\subsection{Testing the Inhibitory Effects of Peptaibol Extracts to Strains of Bacteria, Yeasts, and Filamentous Fungi}

For inhibition tests with the bacteria, LB agar medium was incubated at $37{ }^{\circ} \mathrm{C}$ based on the method of Marik et al. [33]. The same protocol was used for the inhibition assays with yeasts and filamentous fungi by using MEA supplemented with yeast extract. Agar plugs cut from the colonies of the fungal strains were placed in the centre of the plates and holes $(5 \mathrm{~mm}$ in diameter) were bored around in $3 \mathrm{~cm}$ distance from the centre of the plate. Two-fold dilution series of the $100 \mathrm{mg} \mathrm{mL}^{-1}$ crude peptaibol extracts—which were also examined for their peptaibol composition-were tested, with methanol as control. The cultures were incubated at $25^{\circ} \mathrm{C}$. Photographs were taken with a Nikon Coolpix S2600 camera at two stages, when the edge of the culture reached the control hole and when it reached the edge of the Petri-dishes. Three parallel experiments were set up to measure the inhibition zones.

\section{Results and Discussion}

\subsection{Identification, Sequencing, and Quantitation of Peptaibol Compounds Produced by T. gamsii and T. koningiopsis}

Peptaibols produced by the examined species were identified based on the protocol described by Marik et al. [34]. The sequences were determined based on the observation of the characteristic ions of the compounds $\left([\mathrm{M}+\mathrm{Na}]^{+},[\mathrm{M}+2 \mathrm{Na}]^{2+}, \mathrm{b}_{12}\right.$ and $\mathrm{y}_{7}$ ion) and the retention time. The $\mathrm{b}_{\mathrm{n}}$ fragments could be identified after the MS measurements, while the $\mathrm{y}_{7}$ fragments could only be observed after $\mathrm{MS}^{2}$ investigations. The characteristic mass difference $\Delta \mathrm{m}=213 \mathrm{Da}$ could be observed in all MS spectra, resulting from the Gln6-Aib7 bond due to its stability under the fragmentation conditions of ESI-MS [35-37]. The $b_{14}$ fragments were not detected on the MS spectra after the Aib-Pro bond between positions 12 and 13, furthermore, the y7-AA(19-15) ions could also not be detected with $\mathrm{MS}^{2}$, therefore the amino acids in positions 14 and 15 (Vxx14-Aib15) were predicted based on the Comprehensive Peptaibotics Database showing the frequent presence of the Aib-Pro-Vxx-Aib motif in this region [14]. The sequences of the compounds identified from the two examined strains and listed in Tables 1 and 2 are derived from de novo MS-based sequencing. As no amino acid analysis 
has been performed, a discrimination between isobaric amino acids was not possible. The diagnostic fragment ions of the peptaibols found in this study are shown in Tables S1-S4, presented according to Röhrich et al. [38]. The peptaibols produced by T. gamsii SZMC 1656 strain (Table 1, Figures S1, S3 and S5) proved to be completely different from the ones detected in the extract of T. koningiopsis SZMC 12500 (Table 2, Figures S2, S4 and S5). The main differences between the peptaibols of the two species could be identified in 4 positions of their sequences. In the 2 nd position, peptaibols produced by T. gamsii SZMC 1656 contain Gly or Ala in Pept-X, -XI, and -XII, while only Ala was observed in this position in the peptaibol sequences identified from T. koningiopsis SZMC 12500. Another difference is at the 5th residue of the sequences, where mostly Lxx (Leu/Ile), in some cases Vxx (Val/Iva) was identified in the sequences of T. gamsii SZMC 1656, while the compounds of T. koningiopsis SZMC 12500 exhibited mostly Aib at this position. The third main difference between the sequences of the two examined species was observed at the 9th position, where mostly Aib was identified in the peptaibols produced by T. gamsii SZMC 1656, while those from T. koningiopsis SZMC 12500 mostly showed Lxx and in some cases Aib. The 18th position contains Gln in the sequences of T. gamsii SZMC 1656, but T. koningiopsis SZMC 12500 produces compounds with Glu in this position causing 2 more variants of the $\mathrm{y}_{7}$ ion. The sequences Pept-Vb,-VIb, and -VII were matching with trikoningin KA V, though the isomeric positions of Vxx and Lxx were not identified. All other sequences proved to be new and showed similarities to the peptaibol groups of trikoningins, tricholongins, trichostrigocins, and trichorzianins. Apart from the groups shown in Table 1, the newly identified sequences also showed high similarity to trichorzin HAs, which, however, are only 18-residue peptaibols devoid of the Gln/Glu residue [39].

Trikoningin KA V, identified firstly from T. koningii [40], is a peptaibol sequence positionally isomeric with sequences Pept- $\mathrm{Vb},-\mathrm{VIb}$, and $-\mathrm{VII}$. This compound was also found to be produced by T. koningiopsis, along with the 11-residue lipopeptaibols trikoningin KB I and KB II [18]. Trichostrigocins were previously identified from T. strigosum [41-43] and later also from the extracts of T. paraviridescens and T. trixiae as trichostrigocin-like compounds [26]. Tricholongins were detected in T. longibrachiatum [44] and T. strigosum [41], while trichorzianins are known from T. atroviride [45-48]. Further 19-residue peptaibols closely related to those of the present study include hypophellins from T. phellinicola (syn. Hypocrea phellinicola), hypopulvins from T. pulvinatum (syn. H. pulvinata), gelatinosins from T. gelatinosum (syn. H. gelatinosa), voglmayrins from T. voglmayrii (syn. H. voglmayrii), minutisporins from T. minutisporum (syn. H. minutispora) and hypocitrins from T. citrinum (syn. H. citrina) $[38,48,49]$. This indicates that within the genus the ability to produce 19-residue peptaibols is not restricted to clade Viride of section Trichoderma, but also occurring in sections Hypocreanum (T. phellinicola, T. pulvinatum, T. citrinum) and Pachybasium (T. minutisporum), as well as in lone lineages (T. voglmayrii, T. gelatinosum). 
Table 1. Sequences of the newly identified peptaibol compounds produced by T. gamsii SZMC 1656 and their similarities to known peptaibols available in the "Peptaibiotics Database".

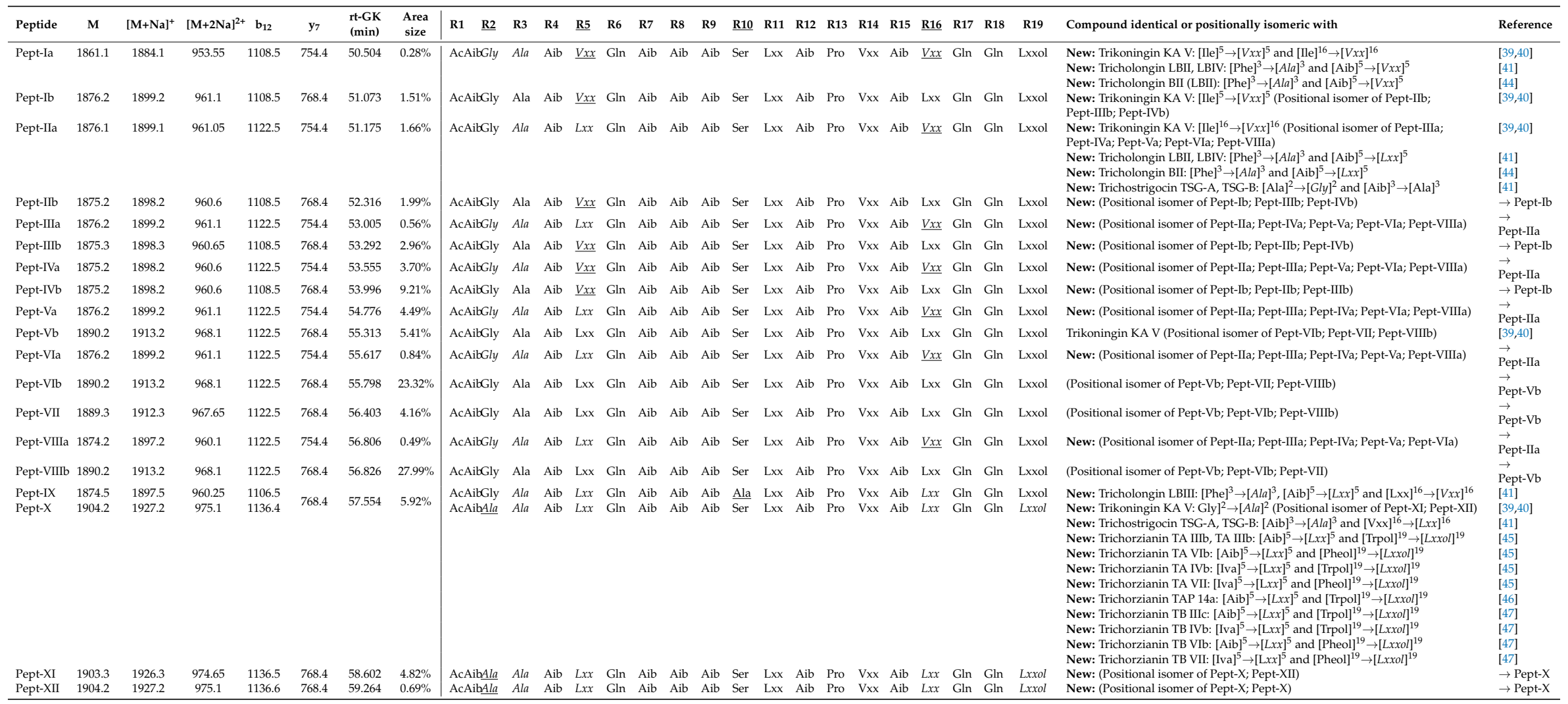

Variable residues are underlined in the table header, minor sequence variants are underlined in the sequences. Amino acid exchanges in new sequences are italicised. 
Table 2. Sequences of the newly identified peptaibol compounds produced by T. koningiopsis SZMC 12500 and their similarities to known peptaibols available in the "Peptaibiotics Database".

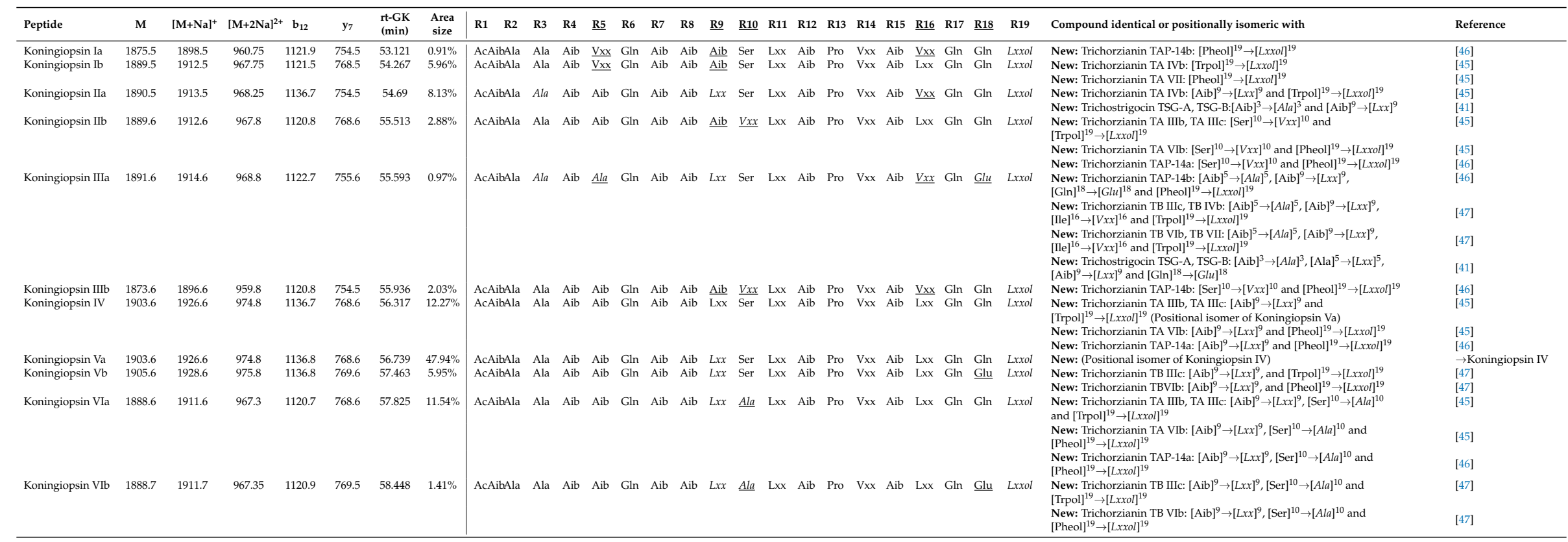

Variable residues are underlined in the table header, minor sequence variants are underlined in the sequences. Amino acid exchanges in new sequences are italicised. Positions R14 and R15 were predicted based on the Comprehensive Peptaibotics Database [14]. 
In certain cases, minor differences were observed between the presently detected and the previously reported peptaibol sequences showing amino acid exchanges only at selected positions of the peptide chain (Tables 1 and 2). Trichorzianins differ in the position 19 of the peptide chain. This position plays a critical role in the lifetime of the opened ion channel as the substitution of Pheol to Leuol/Ileol has led to increased lifetime of the open channel [50]. This was also observed previously in the case of peptaibol-formed channels, where the Pheol was substituted to Trpol in both trichorzianin B-IIIc (Trpol) and B-VII (Pheol) [51]. On the other hand, the investigation of synthetic alamethicin analogues-where all Aib residues were changed to Leu-revealed that the substitution of the C-terminal residues was not affecting the lifetime of the open channel [52]. A secondary structural study was also carried out for the purified compound trichorzianin TA VII in association with sodium dodecyl sulfate (SDS) micelles, which revealed formation of two right-handed helical segments (1-8 and 11-19) linked by a $\beta$-turn [53]. The novelty of the peptaibols produced by T. koningiopsis SZMC 12500 is in the variation of the C-terminus, which is critical in the lifetime of the ion channels. The name "Koningiopsin" was introduced for these novel compounds.

The calculated contents of the whole peptaibol molecules were $214.28 \mu \mathrm{g} \mathrm{mL}{ }^{-1}$ and $101.26 \mu \mathrm{g} \mathrm{mL}^{-1}$ in the crude extracts of T. gamsii SZMC 1656 and T. koningiopsis SZMC 12500, respectively. In the case of $T$. gamsii SZMC 1656, Pept VIIIb and Pept VIb were the most abundant sequences of peptaibols. The sum of the amount of these two molecules was approx. $50 \%$, while the concentration of other peptaibols remained below 10\%. In the extract of T. koningiopsis SZMC 12500, Pept XVIIa accounted for almost half of the peptaibols produced. A new method for quantification of peptaibols based on the length of different peptides was described by Van Bohemen et al. [54]. The different length of peptaibols results in different structures, furthermore, shorter peptaibols (11-14 residues) contain more Pro leading to a structural deformation [55]. Based on the alamethicin standard, only the longer (17-20-residue) peptaibols can be quantified with high accuracy.

\subsection{Structural Elucidation of Trikoningin KA V Based on Short Molecular Dynamics}

Trikoningin KA V (TKV, positionally isomeric with sequences Pept-Vb, -VIb, and -VII of T. gamsii) is a 19-residue peptaibol with seven Aib residues constituting its sequence. Aib is an achiral residue, which has been shown to promote helix formation and can exist in both right- and left-handed helix regions on the Ramachandran plot [56-59]. To determine the propensities of each residue for a given secondary structural region on the Ramachandran plot, their relative free energies were calculated, which clearly describe an energetically favourable conformation (Figure 1). The darkest scatter populations indicate energetically preferable conformations.

Unexpectedly, a strong preference was found for the left-handed helix region of $\Phi-\psi$ plots during this simulation, specifically for residues in the central region flanked by Gln6, Aib7, Aib8, Aib9, Aib12, Val14, Aib15, and Ile16. Except for Aib1 and Aib4, all other Aib residues show free energy minimum in the left-handed helix region. Most standard (proteinogenic) amino acid residues, Gly2, Ala3, Ser10, Leu11, Gln17, and Gln18, display an energy minimum in the right-handed $\alpha$-helix region. Ile5, Ser10, Leu11, Pro13, and Ile16 also show preference for a poly-proline II region. This behaviour of Leu and Ile to occupy $\beta$-space on the Ramachandran plot is expected due to $\beta$-branching of their side-chains. It is known that due to heavy side chains, they show lesser propensity to exist in a helix and, therefore, prefer formation of $\beta$-strands. The presence of three consecutive Aib residues in positions 7,8 , and 9 of the peptide chain seems to drive its conformation towards a left-handed helix, while the rest shows clear preference for right-handedness. This resulted in an overall unwinding of the helix, which never seems to form a continuous spiral shape. Further experiments with higher sampling power are required to confirm these results. The calculation of root-mean-square-deviation (RMSD) values based on the coordinates of peptide backbone atoms $\mathrm{C}, \mathrm{CA}$, and $\mathrm{N}$ for each frame with respect to the average structure has been provided. A similar result was obtained for radius of gyration (RoG) values, which is the root-mean-square-distance of peptide components from their center of mass calculated for each frame. The preliminary investigation revealed that the overall conformation (obtained from the 
trajectory with RMSD value between 12 to $14 \AA$, denoted by structures 3 and 4) resembles a hairpin with turn structures that never assumes a spiral shape (Figure 2A). Structures 2 and 5 with an almost linear structure show lower RMSD values than $12 \AA$, which is not energetically favoured. The free-energy landscape as a function of RMSD and radius of gyration is shown in Figure 2B, which clearly indicates that structures with RoG value of less than $8 \AA$ and RMSD values between $12-14 \AA$ are energetically favoured. When compared with the hydrogen bonding pattern within the backbone, mostly $i+3 \rightarrow i$ H-bonds were found that denote $3_{10}$ helix probably in left-handed conformation as indicated by $\Phi-\psi$ plots (Table 3). Ile5 $\rightarrow$ Gly2, Aib8 $\rightarrow$ Ile5, Aib9 $\rightarrow$ Gln6, Ser10 $\rightarrow$ Aib7, Ile16 $\rightarrow$ Pro13, and Gln17 $\rightarrow$ Val14 are examples of left-handed 310 helix bonds while Gln6 $\rightarrow$ Ala3, Leuol19 $\rightarrow$ Ile16, Leu11 $\rightarrow$ Aib8 are examples of right-handed 310 helix. Few $\gamma$-turn populations are also seen by Aib7 $\rightarrow$ Ile5, Aib12 $\rightarrow$ Ser10, and Gln17 $\rightarrow$ Aib15 as energetically stable. This means that the highly bent structure resembling a $\beta$-hairpin with the $\mathrm{N}$ - and $\mathrm{C}$-terminals in close proximity to each other is energetically favoured in comparison to a linear backbone.

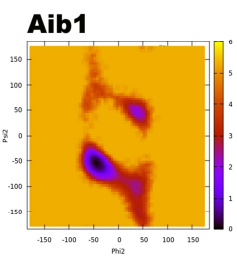

Aib4

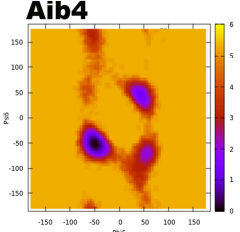

Aib7

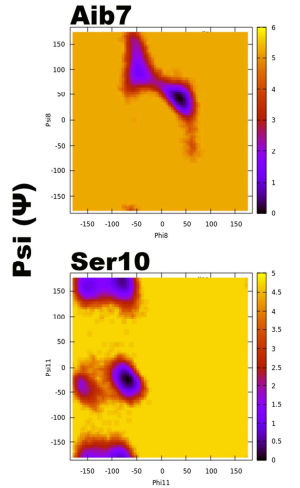

Pro13
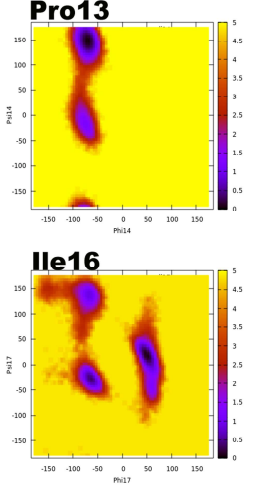

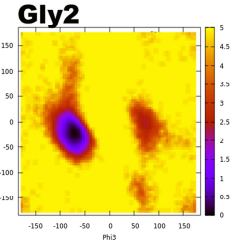

lle5

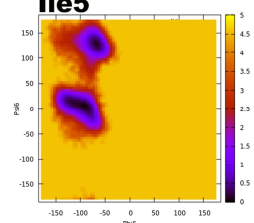

Aib8

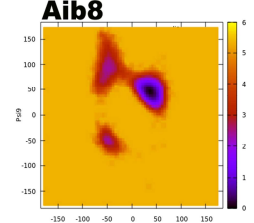

Leu11

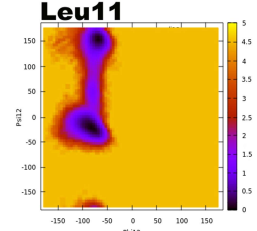

Val14

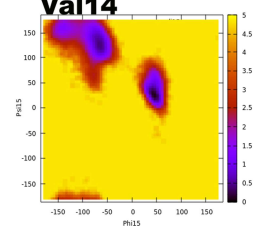

Gln17

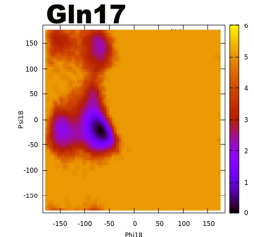

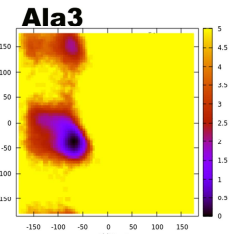

GIn6

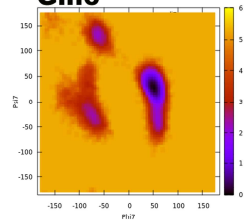

Aib9
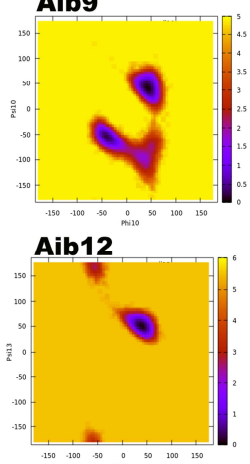

Aib15

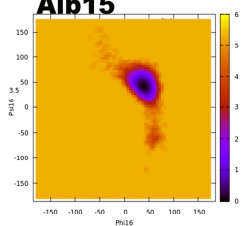

GIn18

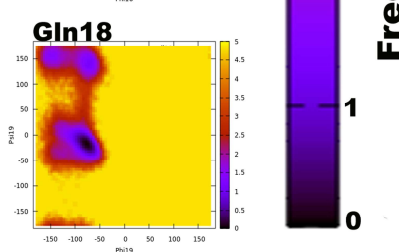

$x$ axis: -180 to 180

$y$ axis: -180 to 180

Phi (Ф)

Figure 1. Free energy-based Ramachandran plots for each Trikoningin KA V residue during $100 \mathrm{~ns}$ long implicit water simulation. The $\mathrm{x}$ and $\mathrm{y}$ axes range from -180 to +180 . The darkest red regions indicate toward minimum energy secondary structural regions favoured by each residue during the simulation. 


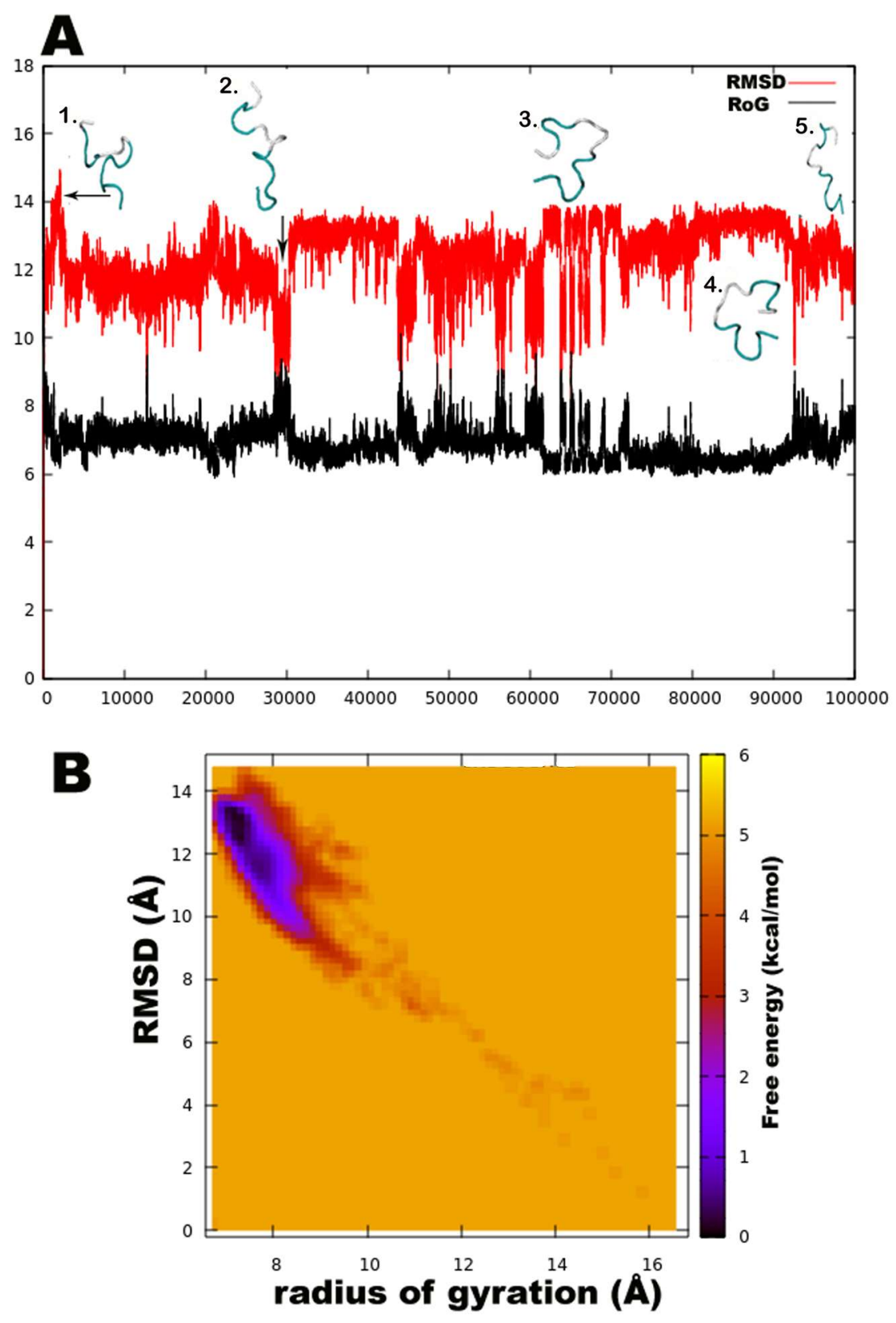

Figure 2. (A). The root-mean-square-deviation (RMSD in red color) and radius of gyration (RoG in black) with corresponding three-dimensional structures of trikoningin KA V, (B). Free energy landscape as a function of RMSD and RoG shows energetically favoured conformations with RMSD between 12-14 ̊̊ and RoG value less than $8 \AA$. 
Table 3. Backbone H-bonds of Trikoningin KA V along with their frequency of occurrence given by fraction, average distance, and angle.

\begin{tabular}{cccc}
\hline Acceptor & Donor & Fraction & Average Distance \\
\hline Gly_2 & Aib_7 & 0.2038 & 2.8926 \\
Gln_6 & Aib_9 & 0.1888 & 2.8999 \\
Ala_3 & Gln_6 & 0.175 & 2.8978 \\
Pro_13 & Ile_16 & 0.1729 & 2.8903 \\
Ile_16 & Leu_19 & 0.1611 & 2.8976 \\
Aib_8 & Leu_11 & 0.1475 & 2.8926 \\
Aib_7 & Ser_10 & 0.1211 & 2.8964 \\
Val_14 & Gln_17 & 0.0917 & 2.9024 \\
Ile_5 & Aib_8 & 0.0727 & 2.912 \\
Aib_15 & Gln_17 & 0.0642 & 2.8104 \\
Aib_15 & Gln_18 & 0.0546 & 2.9034 \\
Ile_16 & Gly_2 & 0.0457 & 2.8761 \\
Aib_15 & Gln_6 & 0.0418 & 2.8816 \\
Ser_10 & Aib_12 & 0.0393 & 2.846 \\
Ile_5 & Aib_7 & 0.0352 & 2.8111 \\
Gly_2 & Ile_5 & 0.0344 & 2.9118 \\
Gln_18 & Val_14 & 0.0316 & 2.851 \\
Gln_17 & Gly_2 & 0.0303 & 2.878 \\
AIB_8 & AIB_12 & 0.0303 & 2.9031 \\
\hline
\end{tabular}

\subsection{Inhibitory Effects of Peptaibol Extracts Towards Bacteria, Yeasts, and Filamentous Fungi}

Micrococcus luteus and S. aureus proved to be sensitive to both peptaibol extracts (Table 4), E. coli was more resistant, while $P$. aeruginosa showed higher sensitivity to the extracts from T. koningiopsis than to those from T. gamsii. M. luteus and S. aureus are Gram-positive bacteria, while E. coli and $P$. aeruginosa are Gram-negative ones, thus their sensitivity showed correlation with the type of their cell wall. Studies on the bioactivity of paracelsins [60] or alamethicin [61] showed similar results, i.e., that Gram-positive bacteria proved to be more sensitive to peptaibols. Testing the peptaibols trichorzianine A1 and B1 on Gram-positive and Gram-negative bacteria also revealed similar results, furthermore, synergistic effect could also be detected between peptaibols and different cell membrane-affecting (MACs) and cell wall-degrading enzymes (CWDEs) [62,63]. In a study of Lorito et al. [64], the inhibition of $\beta$-D-glucan synthase was reported as a specific effect of peptaibol antibiotics. On the other hand, in the study of Cutler et al. [65], the purified peptaibol identified as trikoningin KA V (also known as koningin A) seemed to be inactive against both Gram-positive and Gram-negative bacteria. No inhibition zones could be observed in the case of yeasts (Table 4), though in another study, minimum inhibition could be observed after the treatment of trichokonins produced by T. koningii on S. cerevisiae CGMCC2.395 and C. albicans CGMCC2.538 [66]. Complete inhibition could not be observed among the fast-growing fungi (Table 5), though. Interestingly, the producer T. koningiopsis and T. gamsii strains seemed to be more sensitive to their own peptaibol extracts than T. aggressivum f. europaeum and T. pleuroti, known as the causal agents of green mould disease occurring in mushroom cultivation (Table 5). The latter two species are also known to produce peptaibols [67], but their peptaibiomes are entirely different from those of T. koningiopsis SZMC 12500 and T. gamsii SZMC 1656, they produce 18-residue hypomurocin-like peptaibols and tripleurins, respectively. 
Table 4. Bioactivity of concentrated peptaibol extracts $\left(100 \mathrm{mg} \mathrm{mL}^{-1}\right)$ from Trichoderma gamsii SZMC 1656 and T. koningiopsis SZMC 12500 towards bacteria and yeasts.

\begin{tabular}{ccc}
\hline Tested Microbial Strain & $\begin{array}{c}\text { Sensitivity to T. gamsii SZMC } \\
\text { 1656 Extract }\end{array}$ & $\begin{array}{c}\text { Sensitivity to } \text { T. koningiopsis } \\
\text { SZMC 12500 Extract }\end{array}$ \\
\hline Micrococcus luteus SZMC 0264 & +++++ & ++++ \\
Staphylococcus aureus SZMC 0579 & ++++ & ++++ \\
Escherichia coli SZMC 0582 & + & - \\
Pseudomonas aeruginosa SZMC 0568 & + & ++ \\
Candida boidinii SZMC 0673 & - & - \\
Kluyveromyces lactis SZMC 0683 & - & - \\
Saccharomyces cerevisiae SZMC 0425 & - & - \\
Schizosaccharomyces pombe SZMC 0142 & - & - \\
\hline- , absence of inhibition; diameter of inhibition zone:,$+ 5-7 \mathrm{~mm} ;++, 7-9 \mathrm{~mm},+++, 9-11 \mathrm{~mm},++++, 11-13 \mathrm{~mm}$
\end{tabular}
diameter,,$+++++ 13-15 \mathrm{~mm}$.

Table 5. Bioactivity of concentrated peptaibol extracts $\left(100 \mathrm{mg} \mathrm{mL}^{-1}\right)$ and their two-fold serial dilutions from Trichoderma gamsii SZMC 1656 and T. koningiopsis SZMC 12500 towards cultures of filamentous fungi.

\begin{tabular}{ccc}
\hline Tested Filamentous Fungal Strain & $\begin{array}{c}\text { Sensitivity to T. gamsii SZMC } \\
\text { 1656 Extract }\end{array}$ & $\begin{array}{c}\text { Sensitivity to T. koningiopsis } \\
\text { SZMC 12500 Extract }\end{array}$ \\
\hline Alternaria alternata SZMC 16085 & $+++++*$ & ++ \\
Fusarium solani species complex SZMC 11467 & $++{ }^{*}$ & ++ \\
Rhizoctonia solani SZMC 6252J & ++ & + \\
Phoma cucurbitacearum SZMC 16088 & ++ & ++ \\
T. aggressivum f. europaeum SZMC 1811 & ++ & $+++{ }^{*}$ \\
T. pleuroti SZMC 12454 & +++ & + \\
T. gamsii SZMC 1656 & +++ & +++ \\
T. koningiopsis SZMC 12500 & +++ \\
\hline
\end{tabular}

inhibition of mycelial growth at dilution steps:,+ 1 st -2 nd $;++, 3$ rd -4 th;,+++ 5 th;,++++ 6 th;,+++++ 7 th. ${ }^{*}$, mycelial growth was completely stopped.

The F. solani species complex member appeared to be more sensitive to the peptaibol extract of T. gamsii than to the one of T. koningiopsis. Inhibition could also be detected in the case of A. alternata, R. solani and P. cucurbitacearum, all growing very slowly ( 8 days, 12 days, and 11 days, respectively, till they reach the $\mathrm{MeOH}$ hole on the plates), and interestingly, the mycelial growth of these filamentous fungi stopped where the peptaibols were added into the holes and could not reach the edge of the plates (Table 5).

\section{Conclusions}

In this study, the peptaibiome composition of T. koningiopsis and T. gamsii was identified by HPLC-ESI-MS measurements, which revealed a total of 30 peptaibol sequences. A structurally close compound, trikoningin $\mathrm{KA} \mathrm{V}$, was selected from the literature for structural elucidation, which revealed fluctuating right- and left-handed helical conformations. The examination of their antibiotic activity against a broad spectrum of different microorganisms showed that Gram-positive bacteria were strongly inhibited, while Gram-negative bacteria seemed to be less sensitive to the peptaibol extracts tested. Inhibitory effects of the studied peptaibol extracts could not be observed on yeasts, while filamentous fungi showed considerable sensitivity.

Supplementary Materials: The following are available online at http:/ / www.mdpi.com/2076-2607/6/3/85/s1, Supplementary Data 1: Detailed description for residue parameterization, Figure S1: Extracted ion chromatograms (EIC) resulting from full scan measurements of crude extracts from T. gamsii SZMC 1656, Figure S2: Extracted ion chromatograms (EIC) resulting from full scan measurements of crude extracts prepared from T. koningiopsis SZMC 12500, Figure S3: Typical b ion series of described peptaibols ranged from $b_{12}$ at $m / z 1106$, Figure S4: Typical b ion series of described peptaibols ranging from $b_{12}$ at $m / z 1120$, Figure S5: Typical MS ${ }^{2}$ spectra of y-ions 754.5 (A), 755.5 (B), 768.5 (C) and 769.5 (D) resulting from the full scan measurements of crude peptaibol extracts, Table S1: Diagnostic fragment ions of peptaibols detected with the full scan MS measurement of peptaibol extracts from 
plate cultures of T. gamsii SZMC 1656, Table S2: Diagnostic fragment ions of peptaibols detected with the full scan MS measurement of peptaibol extracts from plate cultures of T. koningiopsis SZMC 12500, Table S3: Diagnostic fragment ions of acylium ion $\left(\mathrm{y}_{7}\right)$ detected with $\mathrm{MS}^{2}$ measurements of peptaibol extracts from plate cultures of T. gamsii SZMC 1656, Table S4: Diagnostic fragment ions of acylium ion ( $\mathrm{y}_{7}$ ) detected with $\mathrm{MS}^{2}$ measurements of peptaibol extracts from plate cultures of T. koningiopsis SZMC 12500.

Author Contributions: Conceptualization, A.S., C.V., L.K.; Data analysis, T.M., C.T., G.R., D.R.; Funding acquisition, A.S., C.V., L.K.; Investigation, T.M., G.R., D.R., A.S.; Methodology, T.M., G.R., D.R., A.S.; Project administration, A.S., C.V., L.K.; Resources, AS., C.V., L.K.; Software, C.T.; Supervision, A.S., C.V., L.K.; Validation, D.R., A.S.; Visualization, T.M., C.T.; Writing—original draft, T.M.; Writing-review \& editing, A.S., C.V., L.K.

Funding: This research was funded by grant GINOP-2.3.2-15-2016-00012 (Széchenyi 2020 Programme). LK was supported by the János Bolyai Research Scholarship (Hungarian Academy of Sciences). AS was supported by the New National Excellence Program of the Ministry of Human Capacities (ÚNKP-16-4).

Conflicts of Interest: The authors declare no conflict of interest.

\section{References}

1. Bissett, J.; Gams, W.; Jaklitsch, W.; Samuels, G.J. Accepted Trichoderma names in the year 2015. IMA Fungus 2015, 6, 263-295. [CrossRef] [PubMed]

2. Bisby, G.R. Trichoderma viride Pers. ex Fries, and notes on Hypocrea. Mycol. Res. 1939, 23, 149-168. [CrossRef]

3. Rifai, M.A. A revision of the genus Trichoderma. Mycol. Pap. 1969, 116, 1-56.

4. Bissett, J. A revision of the genus Trichoderma. II. Infrageneric classification. Can. J. Bot. 1991, 69, $2357-2372$. [CrossRef]

5. Kullnig-Gradinger, C.M.; Szakacs, G.; Kubicek, C.P. Phylogeny and evolution of the genus Trichoderma: A multigene approach. Mycol. Res. 2002, 106, 757-767. [CrossRef]

6. Samuels, G.J.; Dodd, S.L.; Lu, B.S.; Petrini, O.; Schroers, H.J.; Druzhinina, I.S. The Trichoderma koningii aggregate species. Stud. Mycol. 2006, 56, 67-133. [CrossRef] [PubMed]

7. Lieckfeldt, E.; Samuels, G.J.; Nirenberg, H.I.; Petrini, O. A morphological and molecular perspective of Trichoderma viride: Is it one or two species? Appl. Environ. Microbiol. 1999, 65, 2418-2428. [PubMed]

8. Jaklitsch, W.M.; Samuels, G.J.; Dodd, S.L.; Lu, B.S.; Druzhinina, I.S. Hypocrea rufa/Trichoderma viride: A reassessment, and description of five closely related species with and without warted conidia. Stud. Mycol. 2006, 56, 135-177. [CrossRef] [PubMed]

9. Kredics, L.; Hatvani, L.; Naeimi, S.; Körmöczi, P.; Manczinger, L.; Vágvölgyi, C.; Druzhinina, I. Biodiversity of the genus Hypocrea/Trichoderma in different habitats. In Biotechnology and biology of Trichoderma; Gupta, V.K., Schmoll, M., Herrera-Estrella, A., Upadhyay, R.S., Druzhinina, I., Tuohy, M.G., Eds.; Elsevier: New York, NY, USA, 2014; pp. 3-24. ISBN 978-0-444-59576-8.

10. Verma, M.; Brar, S.K.; Tyagi, R.D.; Surampalli, R.Y.; Valéro, J.R. Antagonistic fungi, Trichoderma spp.: Panoply of biological control. Biochem. Eng. J. 2007, 37, 1-20. [CrossRef]

11. Schuster, A.; Schmoll, M. Biology and biotechnology of Trichoderma. Appl. Microbiol. Biotechnol. 2010, 87, 787-799. [CrossRef] [PubMed]

12. Reino, J.L.; Guerrero, R.F.; Hernández-Galán, R.; Collado, I.G. Secondary metabolites from species of the biocontrol agent Trichoderma. Phytochem. Rev. 2008, 7, 89-123. [CrossRef]

13. Degenkolb, T.; Brückner, H. Peptaibiomics: Towards a myriad of bioactive peptides containing C(alpha)-dialkylamino acids? Chem. Biodivers. 2008, 5, 1817-1843. [CrossRef] [PubMed]

14. Stoppacher, N.; Neumann, N.K.N.; Burgstaller, L.; Zeilinger, S.; Degenkolb, T.; Brückner, H.; Schuhmacher, R. The comprehensive peptaibiotics database. Chem. Biodivers. 2013, 10, 734-743. [CrossRef] [PubMed]

15. Marahiel, M.A. Protein templates for the biosynthesis of peptide antibiotics. Chem. Biol. 1997, 4, 561-567. [CrossRef]

16. Bushley, K.E.; Turgeon, B.G. Phylogenomics reveals subfamilies of fungal nonribosomal peptide synthetases and their evolutionary relationships. BMC Evol. Biol. 2010, 10, 26. [CrossRef] [PubMed]

17. Duclohier, H. Helical kink and channel behaviour: A comparative study with the peptaibols alamethicin, trichotoxin and antiamoebin. Eur. Biophys. J. 2004, 33, 169-174. [CrossRef] [PubMed]

18. McMullin, D.R.; Renaud, J.B.; Barasubiye, T.; Sumarah, M.W.; Miller, J.D. Metabolites of Trichoderma species isolated from damp building materials. Can. J. Microbiol. 2017, 63, 621-632. [CrossRef] [PubMed] 
19. Ding, G.; Wang, H.L.; Chen, L.; Chen, A.J.; Lan, J.; Chen, X.D.; Zhang, H.W.; Chen, H.; Liu, X.Z.; Zou, Z.M. Cytochalasans with different amino-acid origin from the plant endophytic fungus Trichoderma gamsii. J. Antibiot. 2012, 65, 143-145. [CrossRef] [PubMed]

20. Ding, G.; Chen, L.; Chen, A.; Tian, X.; Chen, X.; Zhang, H.; Chen, H.; Liu, X.Z.; Zhang, Y.; Zou, Z.M. Trichalasins C and D from the plant endophytic fungus Trichoderma gamsii. Fitoterapia 2012, 83, 541-544. [CrossRef] [PubMed]

21. Ding, G.; Wang, H.; Li, L.; Song, B.; Chen, H.; Zhang, H.; Liu, X.; Zou, Z. Trichodermone, a spiro-cytochalasan with a tetracyclic nucleus $(7 / 5 / 6 / 5)$ skeleton from the plant endophytic fungus Trichoderma gamsii. J. Nat. Prod. 2014, 77, 164-167. [CrossRef] [PubMed]

22. Chen, L.; Liu, Y.T.; Song, B.; Zhang, H.W.; Ding, G.; Liu, X.Z.; Gu, Y.C.; Zou, Z.M. Stereochemical determination of new cytochalasans from the plant endophytic fungus Trichoderma gamsii. Fitoterapia 2014, 96, 115-122. [CrossRef]

23. Ding, G.; Chen, L.; Zhou, C.; Jia, H.M.; Liu, Y.T.; Chang, X.; Song, B.; Liu, X.Z.; Gu, Y.C.; Zou, Z.M. Trichoderamides A and B, a pair of stereoisomers from the plant endophytic fungus Trichoderma gamsii. J. Antibiot. 2015, 68, 409-413. [CrossRef] [PubMed]

24. Chen, L.; Niu, S.B.; Li, L.; Ding, G.; Yu, M.; Zhang, G.S.; Wang, M.H.; Li, L.Y.; Zhang, T.; Jia, H.M.; et al. Trichoderpyrone, a unique polyketide hybrid with a cyclopentenone-pyrone skeleton from the plant endophytic fungus Trichoderma gamsii. J. Nat. Prod. 2017, 80, 1944-1947. [CrossRef] [PubMed]

25. Chen, J.L.; Sun, S.Z.; Miao, C.P.; Wu, K.; Chen, Y.W.; Xu, L.H.; Guan, H.L.; Zhao, L.X. Endophytic Trichoderma gamsii YIM PH30019: A promising biocontrol agent with hyperosmolar, mycoparasitism, and antagonistic activities of induced volatile organic compounds on root-rot pathogenic fungi of Panax notoginseng. J. Ginseng Res. 2016, 40, 315-324. [CrossRef] [PubMed]

26. Castagnoli, E.; Marik, T.; Mikkola, L.; Kredics, L.; Andersson, M.A.; Salonen, H.; Kurnitski, J. Indoor Trichoderma strains emitting peptaibols in guttation droplets. J. Appl. Microbiol. 2018. [CrossRef] [PubMed]

27. Vanquelef, E.; Simon, S.; Marquant, G.; Garcia, E.; Klimerak, G.; Delepine, J.C.; Cieplak, P.; Dupradeau, F.Y. RED Server: A web service for deriving RESP and ESP charges and building force field libraries for new molecules and molecular fragments. Nucleic Acids Res. 2011, 39, 511-517. [CrossRef] [PubMed]

28. Dupradeau, F.Y.; Pigache, A.; Zaffran, T.; Savineau, C.; Lelong, R.; Grivel, N.; Lelong, D.; Rosanski, W.; Cieplak, P. The REd. Tools: Advances in RESP and ESP charge derivation and force field library building. Phys. Chem. Chem. Phys. 2010, 12, 7821-7839. [CrossRef] [PubMed]

29. Cieplak, P.; Cornell, W.D.; Bayly, C.; Kollman, P.A. Application of the multimolecule and multiconformational RESP methodology to biopolymers: Charge derivation for DNA, RNA, and proteins. J. Comput. Chem. 1995, 16, 1357-1377. [CrossRef]

30. Case, D.A.; Ben-Shalom, I.Y.; Brozell, S.R.; Cerutti, D.S.; Cheatham, T.E., III; Cruzeiro, V.W.D.; Darden, T.A.; Duke, R.E.; Ghoreishi, D.; Gilson, M.K.; et al. Amber 2018 Reference Manual; University of California: San Francisco, CA, USA, 2018.

31. Humphrey, W.; Dalke, A.; Schulten, K. VMD: Visual molecular dynamics. J. Mol. Graph. 1996, 14, $33-38$. [CrossRef]

32. Roe, D.R.; Cheatham III, T.E. PTRAJ and CPPTRAJ: Software for processing and analysis of molecular dynamics trajectory data. J. Chem. Theory. Comput. 2013, 9, 3084-3095. [CrossRef] [PubMed]

33. Marik, T.; Szekeres, A.; Várszegi, C.; Czifra, D.; Vágvölgyi, C.; Kredics, L. Rapid bioactivity-based pre-screening method for the detection of peptaibiotic-producing Trichoderma strains. Acta Biol. Szeged. 2013, 57, 1-7.

34. Marik, T.; Várszegi, C.; Kredics, L.; Vágvölgyi, C.; Szekeres, A. Mass spectrometric investigation of alamethicin. Acta Biol. Szeged. 2013, 57, 109-112.

35. Jaworski, A.; Kirschbaum, J.; Brückner, H. Structures of trichovirins II, peptaibol antibiotics from the mold Trichoderma viride NRRL 5243. J. Pept. Sci. 1999, 5, 341-351. [CrossRef]

36. Kirschbaum, J.; Krause, C.; Winzheimer, R.K.; Brückner, H. Sequences of alamethicins F30 and F50 reconsidered and reconciled. J. Pept. Sci. 2003, 9, 799-809. [CrossRef] [PubMed]

37. Krause, C.; Kirschbaum, J.; Brückner, H. Peptaibiomics: An advanced, rapid and selective analysis of peptaibiotics/peptaibols by SPE/LC-ES-MS. Amino Acids 2006, 30, 435-443. [CrossRef] [PubMed] 
38. Röhrich, C.R.; Iversen, A.; Jaklitsch, W.M.; Voglmayr, H.; Vilcinskas, A.; Nielsen, K.F.; Thrane, U.; von Döhren, H.; Brückner, H.; Degenkolb, T. Screening the biosphere: The fungicolous fungus Trichoderma phellinicola, a prolific source of hypophellins, new 17-, 18-, 19-, and 20-residue peptaibiotics. Chem. Biodivers. 2013, 10, 787-812. [CrossRef] [PubMed]

39. Goulard, C.; Hlimi, S.; Rebuffat, S.; Bodo, B. Trichorzins HA and MA, antibiotic peptides from Trichoderma harzianum. J. Antibiot. 1995, 48, 1248-1253. [CrossRef] [PubMed]

40. Auvin-Guette, C.; Rebuffat, S.; Vuidepot, I.; Massias, M.; Bodo, B. Structural elucidation of trikoningins KA and KB, peptaibols from Trichoderma koningii. J. Chem. Soc. Perkin Trans. I 1993, 249-255. [CrossRef]

41. Degenkolb, T.; Gräfenhan, T.; Berg, A.; Nirenberg, H.I.; Gams, W.; Brückner, H. Peptaibiomics: Screening for polypeptide antibiotics (peptaibiotics) from plant-protective Trichoderma species. Chem. Biodivers. 2006, 3, 593-610. [CrossRef] [PubMed]

42. Degenkolb, T.; Dieckmann, R.; Nielsen, K.F.; Gräfenhan, T.; Theis, C.; Zafari, D.; Chaverri, P.; Ismaiel, A.; Brückner, H.; von Döhren, H.; et al. The Trichoderma brevicompactum clade: A separate lineage with new species, new peptaibiotics, and mycotoxins. Mycol. Prog. 2008, 7, 177-219. [CrossRef]

43. Neuhof, T.; Dieckmann, R.; Druzhinina, I.S.; Kubicek, C.P.; von Döhren, H. Intact-cell MALDI-TOF mass spectrometry analysis of peptaibol formation by the genus Trichoderma/Hypocrea: Can molecular phylogeny of species predict peptaibol structures? Microbiology 2007, 153, 3417-3437. [CrossRef] [PubMed]

44. Rebuffat, S.; Prigent, Y.; Auvin-Guette, C.; Bodo, B. Tricholongins BI and BII, 19-residue peptaibols from Trichoderma longibrachiatum. FEBS J. 1991, 201, 661-674. [CrossRef]

45. Hajji, M.E.; Rebuffat, S.; Lecommandeur, D.; Bodo, B. Isolation and sequence determination of trichorzianines A antifungal peptides from Trichoderma harzianum. Int. J. Pept. Protein Res. 1987, 29, 207-215. [CrossRef] [PubMed]

46. Pócsfalvi, G.; Scala, F.; Lorito, M.; Ritieni, A.; Randazzo, G.; Ferranti, P.; Vékey, K.; Malorni, A. Microheterogeneity characterization of a trichorzianine-A mixture from Trichoderma harzianum. J. Mass Spectrom. 1998, 33, 154-163. [CrossRef]

47. Rebuffat, S.; Hajji, M.; Hennig, P.; Davoust, D.; Bodo, B. Isolation, sequence, and conformation of seven trichorzianines from Trichoderma harzianum. Chem. Biol. Drug Des. 1989, 34, 200-210. [CrossRef]

48. Röhrich, C.R.; Jaklitsch, W.M.; Voglmayr, H.; Iversen, A.; Vilcinskas, A.; Nielsen, K.F.; Thrane, U.; von Döhren, H.; Brückner, H.; Degenkolb, T. Front line defenders of the ecological niche! Screening the structural diversity of peptaibiotics from saprotrophic and fungicolous Trichoderma/Hypocrea species. Fungal Divers. 2014, 69, 117-146. [CrossRef] [PubMed]

49. Röhrich, C.R.; Iversen, A.; Jaklitsch, W.M.; Voglmayr, H.; Berg, A.; Dörfelt, H.; Thrane, U.; Vilcinskas, A.; Nielsen, K.F.; Von Döhren, H.; et al. Hypopulvins, novel peptaibiotics from the polyporicolous fungus Hypocrea pulvinata, are produced during infection of its natural hosts. Fungal Boil. 2012, 116, 1219-1231. [CrossRef] [PubMed]

50. Koide, N.; Asami, K.; Fujita, T. Ion-channels formed by hypelcins, antibiotic peptides, in planar bilayer lipid membranes. Biochim. Biophys. Acta 1997, 1326, 47-53. [CrossRef]

51. Duclohier, H.; Molle, G.; Spach, G. The influence of the trichorzianin C-terminal residues on the ion channel conductance in lipid bilayers. Biochim. Biophys. Acta 1989, 987, 133-136. [CrossRef]

52. Molle, G.; Duclohier, H.; Julien, S.; Spach, G. Synthetic analogues of alamethicin: Effect of C-terminal residue substitutions and chain length on the ion channel lifetimes. Biochim. Biophys. Acta 1991, 1064, 365-369. [CrossRef]

53. Condamine, E.; Rebuffat, S.; Prigent, Y.; Ségalas, I.; Bodo, B.; Davoust, D. Three-dimensional structure of the ion-chanel forming peptide trichorzianin TA VII bound to sodium dodecyl sulfate micelles. Biopolymers 1998, 46, 75-88. [CrossRef]

54. Van Bohemen, A.-I.; Zalouk-Vergnoux, A.; Poirier, L.; Phuong, N.N.; Inguimbert, N.; Salah, K.B.H.; Ruiz, N.; Pouchus, Y.F. Development and validation of LC-MS methods for peptaibol quantification in fungal extracts according to their lengths. J. Chromatogr. B Biomed. Sci. Appl. 2016, 1009-1010, 25-33. [CrossRef] [PubMed]

55. Rebuffat, S.; Goulard, C.; Bodo, B.; Roquebert, M.-F. The peptaibol antibiotics from Trichoderma soil fungi; structural diversity and membrane properties. Recent Res. Devel. Org. Biorg. Chem. 1999, 3, 65-91.

56. Aravinda, S.; Shamala, N.; Balaram, P. Aib residues in peptaibiotics and synthetic sequences: Analysis of nonhelical conformations. Chem. Biodivers. 2008, 5, 1238-1262. [CrossRef] [PubMed] 
57. Mahalakshmi, R.; Balaram, P. The use of D-amino acids in peptide design. In D-Amino Acids: A New Frontier in Amino Acid and Protein Research-Practical Methods and Protocols; Konno, R., Brückner, H., D'Aniello, A., Fisher, G.H., Fujii, N., Homma, H., Eds.; Nova Science Publishers: New York, NY, USA, 2007; pp. 415-430.

58. Wałesa, R.; Broda, M.A. The influence of solvent on conformational properties of peptides with Aib residue-a DFT study. J. Mol. Model. 2017, 23, 349. [CrossRef] [PubMed]

59. Schweitzer-Stenner, R.; Gonzales, W.; Bourne, G.T.; Feng, J.A.; Marshall, G.R. Conformational manifold of $\alpha$-aminoisobutyric acid (Aib) containing alanine-based tripeptides in aqueous solution explored by vibrational spectroscopy, electronic circular dichroism spectroscopy, and molecular dynamics simulations. J. Am. Chem. Soc. 2007, 129, 13095-13109. [CrossRef] [PubMed]

60. Brückner, H.; Graf, H. Paracelsin, a peptide antibiotic containing $\alpha$-aminoisobutyric acid, isolated from Trichoderma ressei Simmons Part A. Experientia 1983, 39, 528-530. [CrossRef] [PubMed]

61. Jen, W.C.; Jones, G.A.; Brewer, D.; Parkinson, V.O.; Taylor, A. The antibacterial activity of alamethicins and zervamicins. J. Appl. Microbiol. 1987, 63, 293-298. [CrossRef]

62. Lorito, M.; Woo, S.L.; D'Ambrosio, M.; Harman, G.E.; Hayes, C.K.; Kubicek, C.P.; Scala, F. Synergistic interaction between cell wall degrading enzymes and membrane affecting compounds. Mol. Plant Microbe Interact. 1996, 9, 206-213. [CrossRef]

63. Benítez, T.; Rincón, A.M.; Limón, M.C.; Codon, A.C. Biocontrol mechanisms of Trichoderma strains. Int. Microbiol. 2004, 7, 249-260. [PubMed]

64. Lorito, M.; Farkas, V.; Rebuffat, S.; Bodo, B.; Kubicek, C.P. Cell wall synthesis is a major target of mycoparasitic antagonism by Trichoderma harzianum. J. Bacteriol. 1996, 178, 6382-6385. [CrossRef] [PubMed]

65. Cutler, H.G.; Himmelsbach, D.S.; Yagen, B.; Arrendale, R.F.; Jacyno, J.M.; Cole, P.D.; Cox, R.H. Koninginin B: A biologically active congener of koninginin A from Trichoderma koningii. J. Agric. Food Chem. 1991, 39, 977-980. [CrossRef]

66. Song, X.Y.; Shen, Q.T.; Xie, S.T.; Chen, X.L.; Sun, C.Y.; Zhang, Y.Z. Broad-spectrum antimicrobial activity and high stability of Trichokonins from Trichoderma koningii SMF2 against plant pathogens. FEMS Microbiol. Lett. 2006, 260, 119-125. [CrossRef]

67. Marik, T.; Urbán, P.; Tyagi, C.; Szekeres, A.; Leitgeb, B.; Vágvölgyi, M.; Manczinger, L.; Druzhinina, I.S.; Kredics, L. Diversity profile and dynamics of peptaibols produced by green mould Trichoderma species in interactions with their hosts Agaricus bisporus and Pleurotus ostreatus. Chem. Biodivers. 2017, 14. [CrossRef] [PubMed]

(C) 2018 by the authors. Licensee MDPI, Basel, Switzerland. This article is an open access article distributed under the terms and conditions of the Creative Commons Attribution (CC BY) license (http:/ / creativecommons.org/licenses/by/4.0/). 